\title{
Carcinoma de Células Acinares da Parótida: Caso Clínico
}

\section{Parotid Acinic Cell Carcinoma: Case Report}

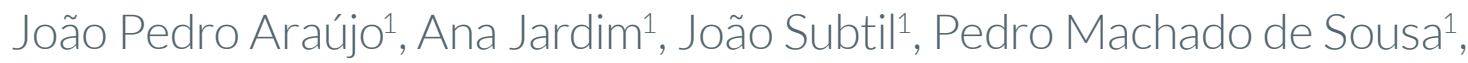
Pedro Montalvão ${ }^{1}$, José Saraiva ${ }^{1}$

\section{RESUMO}

Apresentamos um caso clínico de tumor da parótida - carcinoma de células acinares - envolvendo o lobo superficial e profundo da parótida, tratado cirurgicamente por parotidectomia total e radioterapia adjuvante local e cervical. Escolhemos este caso pelo facto de o tumor envolver o lobo superficial e profundo da parótida, sem envolver o nervo facial, o que constituiu um desafio cirúrgico maior, que foi a remoção do tumor e da glândula preservando o nervo e todos os seus ramos.

No Hospital CUF Descobertas, o tratamento dos doentes com cancro da cabeça e pescoço é assegurado pela colaboração multidisciplinar entre as especialidades de Otorrinolaringologia, Hemato-Oncologia e Radioterapia. Os tumores das glândulas salivares são um exemplo, como demonstrado no caso clínico apresentado.

PALAVRAS-CHAVE: Carcinoma Células Acinares; Neoplasia da Parótida/cirurgia; Neoplasia da Parótida/radioterapia

\section{ABSTRACT}

We present a case of a parotid tumor - acinic cell carcinoma - involving the superficial and deep lobe, surgically treated with total parotidectomy and then submitted to local and cervical radiotherapy.

We have chosen this case due to the fact that the tumor involved both the superficial and deep lobe, without involving the facial nerve. This putted a bigger surgical challenge, which was the removal of the tumor and the gland preserving the nerve and its branches.

At CUF Descobertas Hospital, the treatment of patients with head and neck cancer is assured by the multidisciplinary collaboration of Otorhinolaryngology, Haemato-Oncology and Radiotherapy departments. Salivary glands tumors are one example, as is the case presented.

KEYWORDS: Carcinoma, Acinar Cell; Parotid Neoplasms/radiotherapy; Parotid Neoplasms/sugery 


\section{INTRODUÇÃO}

Os tumores malignos das glândulas salivares são relativamente raros, com uma incidência de 1-2/100 000 nos Estados Unidos da América, e correspondem a cerca de 3\% - 4\% dos tumores da cabeça e pescoço. ${ }^{1}$ Não parecem ter relação com o tabaco e o álcool, e carcinogéneos específicos ainda não foram claramente identificados. ${ }^{1}$ Dentro das glândulas salivares, a parótida é a glândula mais frequentemente afetada (75\% - 80\%), ${ }^{1}$ apesar de apenas aproximadamente $20 \%$ dos tumores da parótida serem malignos. ${ }^{2}$

A cirurgia desta glândula apresenta como grande desafio a preservação do nervo facial, cuja lesão, ao condicionar uma assimetria na mímica facial, tem um impacto negativo na qualidade de vida dos doentes. ${ }^{3} \mathrm{O}$ domínio da complexa anatomia do nervo facial é essencial para a sua identificação e preservação durante a cirurgia. Além disso, pode ser útil a utilização de neuroestimulador e/ou monitorização do nervo intra-operatoriamente, como complemento. ${ }^{4}$ Para tal, na Anestesia, usa-se um relaxante muscular de curta duração, apenas para entubação orotraqueal. ${ }^{4}$

\section{CASO CLÍNICO}

Doente do sexo masculino, 37 anos, saudável, recorreu a consulta de Otorrinolaringologia com história de tumefação indolor do ângulo da mandíbula direita com um mês de evolução. Ao exame objetivo, palpou-se uma tumefação de forma arredondada, localizada aparentemente na região inferior da parótida, de consistência dura, com cerca de $3 \mathrm{~cm}$ de diâmetro, sem sinais inflamatórios cutâneos, aderente aos planos profundos. O doente não apresentava paralisia facial - House-Brackmann grau I.

Foi pedido estudo ecográfico que revelou um nódulo sólido, de $30 \mathrm{~mm}$, do terço inferior da parótida direita, envolvendo a sua vertente superficial.

Foi feita punção aspirativa com agulha fina, revelando histologia sugestiva de adenoma monomórfico, tumor de Warthin ou neoplasia de células acinares.

O caso foi discutido em consulta multidisciplinar oncológica e a decisão terapêutica proposta foi exérese cirúrgica do tumor para tratamento e diagnóstico definitivo, que o doente aceitou.

Foi realizada parotidectomia total. Após dissecção do bordo posterior da parótida identificou-se por via anterógrada o tronco principal do nervo facial na sua emergência do buraco estilo-mastoideu. Para o encontrar utilizaram-se como pontos cardeais o ventre posterior do digástrico, a cartilagem apontadora ("pointer"), apófi-

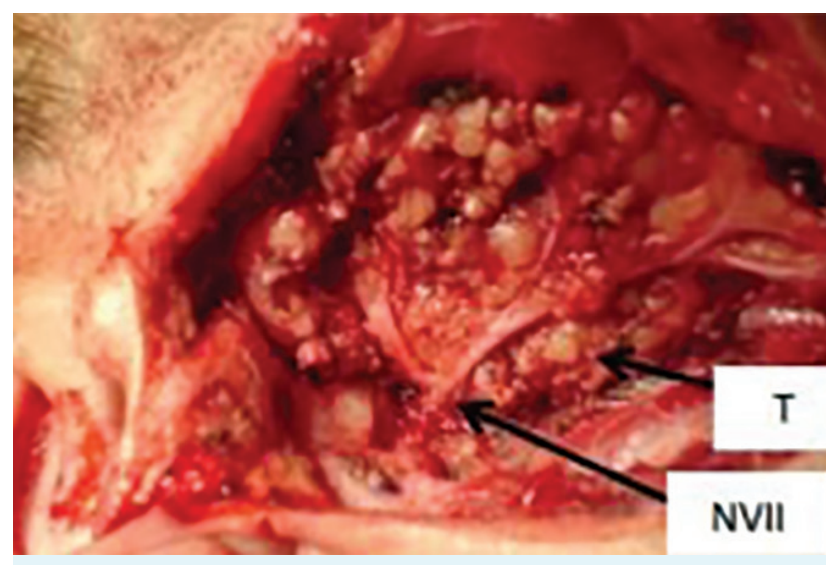

FIGURA 1. Fotografia obtida durante a cirurgia após remoção do lobo superficial da parótida. Identifica-se o nervo facial (NVII) que na espessura da parótida se ramifica nos seus ramos superior e inferior. O tumor ( $\mathrm{T}$ ) envolvia também o lobo profundo.

se estiloideia e a linha da sutura timpanomastoideia. Foi utilizado neuroestimulador para o confirmar, uma vez que o doente não estava sob relaxante muscular. O lobo superficial da parótida foi dissecado e removido, em conjunto com parte do tumor, à medida que se identificaram os vários ramos distais do nervo facial (Fig. 1).

Após a remoção do lobo superficial verificou-se que havia também tumor no lobo profundo, pelo que se tornou imperativo remover o lobo profundo e o resto do tumor nele contido. No fim deste procedimento foram colhidas amostras da margem profunda que se enviaram para Anatomia Patológica. Destaca-se que foi possível identificar e preservar todos os ramos do nervo facial. Utilizando o neuroestimulador confirmou-se também intra-operatoriamente integridade do nervo facial mantida que se confirmou no pós-operatório imediato.

O pós-operatório decorreu sem intercorrências, com mobilidade facial mantida e simétrica, House-Brackmann grau I, e o doente teve alta ao segundo dia de pós-operatório após remoção do dreno.

A análise histológica da peça operatória revelou uma neoplasia maligna epitelial, multinodular, com aspetos que favorecem o diagnóstico de carcinoma de células acinares, de células claras. O nódulo maior media 27 mm, e estava localizado no lobo profundo. Não se observou invasão linfo-vascular ou perineural. A excisão foi justa-lesional em todos os fragmentos. Após realização de tomografia computorizada (TC) cervical e torácica obteve-se um estadiamento T2NOMO. ${ }^{5}$ Pelo facto de se tratar de uma neoplasia de predomínio de células claras, foi sugerido pela Anatomia Patológica, a exclusão clínica de neoplasia primária renal, que não se confirmou por estudo com TC abdominal.

O caso foi novamente discutido em reunião multidisciplinar, e foi sugerida radioterapia adjuvante local e cervical 
que o doente aceitou e realizou neste hospital. Neste momento, passaram três anos desde a cirurgia, e o doente encontra-se bem, sem recidiva loco-regional.

\section{DISCUSSÃO}

No caso clínico apresentado, a única manifestação clínica do tumor da parótida foi uma tumefação indolor, como acontece com a maioria dos doentes, em que clinicamente estes tumores se manifestam como uma massa ou edema indolor achados incidentalmente. Sintomas como dor, paralisia do nervo facial e adenopatias predizem doença localmente avançada e um mau prognóstico. Tumores que envolvem o lobo profundo da parótida podem-se fazer notar como uma massa, frequentemente assintomática, da orofaringe, sem haver uma massa palpável na zona da parótida.

O estudo ecográfico confirma a origem do tumor na parótida e distingue entre massas sólidas e quísticas, e a punção aspirativa com agulha fina dá o diagnóstico histológico com uma sensibilidade de 80\% - 90\% para neoplasias malignas das glândulas salivares. Outros estudos imagiológicos, como a tomografia computorizada (TC) e a ressonância magnética (RM), são úteis na avaliação do tamanho e local do tumor, assim como para estudo da sua extensão regional. São usados também para detetar doença metastática regional, contribuindo assim para o estadiamento. ${ }^{1,2}$ Entre estas duas modalidades a RM é a mais frequentemente recomendada no estudo de neoplasias de glândulas salivares, pois permite meIhor detalhe dos tecidos moles e extensão do tumor. ${ }^{6}$ Com o uso de contraste e saturação da gordura pode-se estudar a extensão do tumor, nomeadamente o envolvimento ósseo e invasão perineural. ${ }^{6} \mathrm{O}$ estudo com TC com contraste endovenoso também é muito usado, e é particularmente útil para avaliar se existe erosão cortical óssea pelo tumor. ${ }^{6}$ Através da identificação imagiológica em RM ou TC da veia retromandibular, que está intimamente associada ao nervo facial, pode-se tentar prever se a massa parotídea se localiza provavelmente no lobo profundo ou superficial da parótida. ${ }^{4}$ No caso descrito recorremos apenas ao estudo ecográfico, cujo relatório nos forneceu informação que considerámos suficiente para partir para cirurgia, nódulo sólido de 30 mm no lobo superficial da parótida. A clínica do doente, não nos fez suspeitar de extensão extra-parenquimatosa, ainda não tínhamos diagnóstico histológico de malignidade, e mesmo em discussão multidisciplinar não foi proposto mais nenhum estudo imagiológico. De facto a investigação radiológica não é necessária por rotina nos tumores da parótida. Está recomendada no planeamento cirúrgico no caso de tumores grandes, fixos, com envolvimento do nervo facial, trismus e envolvimento do espaço pa- rafaríngeo. ${ }^{4}$ Olhando retrospetivamente, em que intra-operatoriamente se encontrou extensão tumoral para o lobo profundo, um estudo por RM pré-operatório para melhor caracterização da localização do tumor teria sido útil no planeamento cirúrgico.

○ caso clínico descrito apresenta a particularidade de a punção aspirativa pré-operatória não ser conclusiva quanto ao diagnóstico de malignidade. A histologia dos tumores malignos das glândulas salivares é muito variada e inclui vários tipos de carcinoma. ${ }^{2}$ Podemos classificá-los em tumores de baixo, intermédio ou alto grau consoante a clínica e o prognóstico. $\bigcirc$ diagnóstico final revelou um carcinoma de células acinares, uma neoplasia classicamente de baixo grau, que corresponde a cerca de 15\% dos tumores malignos da parótida, com elevada sobrevivência7 (78\% aos 5 anos $^{1}$ ), mas com uma história natural longa ${ }^{7}$ (44\% de sobrevivência aos 15 anos $^{1}$ ), sendo reconhecidos pela sua recorrência. ${ }^{6}$ Destes tumores, 10\% a 15\% metastizam para gânglios regionais ou à distância para o pulmão e ossos. ${ }^{6}$

O tratamento de eleição para as neoplasias malignas da parótida é a cirurgia, e recomenda-se parotidectomia total para os tumores malignos, ou estendida nos casos em que o tumor invade estruturas adjacentes. No caso descrito, estava planeada apenas parotidectomia superficial, pois a ecografia mostrava um tumor do lobo superficial, e a histologia não era conclusiva. No entanto, intra-operatoriamente verificou-se que o tumor estava também contido integralmente no lobo profundo. Este facto levou à necessidade de remoção também do lobo profundo, o que é sempre um desafio cirúrgico, pois há que isolar e retrair o nervo facial e seus ramos que atravessam a glândula. De referir que os tumores malignos do lobo profundo são raros. ${ }^{2}$

O nervo facial deve ser preservado nas cirurgias da parótida se não estiver envolvido pelo tumor. ${ }^{2}$ No entanto, sacrifica-se este nervo quando não é possível dissecá-lo do tumor que o invade diretamente, ou quando existe uma parésia ou paralisia pré-operatoriamente. ${ }^{2}$

○ esvaziamento ganglionar cervical está indicado nos tumores clinicamente $\mathrm{N}+$, e deve ser considerado nos tumores de alto grau ou com estadiamento avançado.

Após cirurgia, realiza-se radioterapia adjuvante nos tumores T3 e T4a quando o diagnóstico é um carcinoma adenoide quístico ou quando se encontram achados adversos: tumores de grau intermédio e alto, margens curtas ou positivas, invasão neural/perineural, nódulos linfáticos metastáticos ou invasão linfática/vascular. A radioterapia adjuvante deve ser também considerada nos tumores T1 e T2 de baixo grau em que se encontra invasão perineural, em que o nervo facial está intacto, 
mas as margens de ressecção estão junto ao nervo ou nos casos em que durante a cirurgia possa ter havido sementeira do tumor, e também nos tumores T1 e T2 que sejam de grau intermédio ou alto ou que sejam carcinoma adenoide quístico. ${ }^{2}$ No caso relatado neste artigo é debatível a realização de radioterapia adjuvante, tendo em conta ser um tumor de baixo grau, com excisão completa e sem aparentes achados adversos. Ainda assim, a história natural longa deste tipo de tumores, a proximidade que o tumor tinha com o nervo facial (podendo existir à volta deste, células tumorais microscópicas por remover) e consultando a própria vontade do doente, decidiu-se que poderia ser benéfica a realização de radioterapia adjuvante.

Nos casos em que os doentes recusam cirurgia, em tumores não ressecáveis, ou em que a cirurgia não seja recomendada, e nos tumores com estadiamento T4b o tratamento é a radioterapia (RT) ou quimioterapia associada a RT. ${ }^{3}$

Neste artigo, com um caso clínico clinicamente desafiante, pretendemos dar um exemplo da experiência que o Hospital CUF Descobertas tem tido no tratamento de doentes com cancro da cabeça e pescoço, onde é essencial a colaboração multidisciplinar entre as especialidades de Otorrinolaringologia, Hemato-Oncologia e Radioterapia.

CONSENTIMENTO INFORMADO: Foi obtido o consentimento informado do doente para publicação.

INFORMED CONSENT: The informed consent for publication was obtained from the patient.

CONFLITOS DE INTERESSE: Os autores declaram não ter qualquer conflito de interesse na realização do presente trabalho.

FONTES DE FINANCIAMENTO: Não houve qualquer fonte de financiamento na realização do presente trabalho.

CONFIDENCIALIDADE DOS DADOS: Os autores declaram ter seguido os protocolos da sua instituição acerca da publicação dos dados de doentes.
PROTEÇÃO DE PESSOAS E ANIMAIS: Os autores declaram que os procedimentos seguidos na elaboração do presente trabalho estão em conformidade com as normas das comissões de investigação clínica e de ética, bem como da declaração de Helsínquia e da Associação Médica Mundial.

CONFLICTS OF INTEREST: The authors declare that they have no conflicts of interest.

FINANCIAL SUPPORT: This work has not received any contribution, grant or scholarship.

CONFIDENTIALITY OF DATA: The authors declare that they have followed the protocols of their work center on the publication of data from patients.

PROTECTION OF HUMAN AND ANIMAL SUBJECTS: The authors declare that the procedures followed were in accordance with the regulations of the relevant clinical research ethics committee and with those of the Code of Ethics of the World Medical Association (Declaration of Helsinki).

\section{REFERÊNCIAS}

1. Concus AP, Tran TN. Malignant Diseases of the Salivary Glands. In: Lalwani AK, editor. Current Diagnosis \& Treatment Otolaryngology Head and Neck Surgery. 3rd ed. New York: McGraw-Hill Companies; 2012. p.333-44.

2. National Comprehensive Cancer Network. NCCN Clinical Practice Guidelines in Oncology: Head and Neck Cancers. Version 1.2017 [accessed February 2017]. Available from: https://www.nccn.org/professionals/physician_gls/f_guidelines. asp.

3. Iseli TA, Karnell LH, Preston TW, Graham SM, Funk GF, Buatti JM, et al. Facial nerve sacrifice and radiotherapy in parotid adenoid cystic carcinoma. Laryngoscope. 2008;118:1781-6.

4. Fagan J. Parotidectomy. Cape Town. In: Open Access Atlas of Otolaryngology, Head \& Neck Operative Surgery [accessed February 2017]. Available from: https://vula.uct.ac.za/access/ content/group/ba5fb1bd-be95-48e5-81be-586fbaeba29d/ Parotidectomy-1.pdf.

5. American Joint Committee on Cancer. TNM Staging System for the Major Salivary Glands (Parotid, Submandibular, and Sublingual). 7th ed. New York: AJCC; 2010.

6. Sunwoo JB, Lewis Jr JS, Tomeh C, McJunkin J. Malignant Neoplasmas of the Salivary Glands. In: Flint PW, Haughey BH, Lund VJ, editors. Cummings Otolaryngology - Head and Neck Surgery. $6^{\text {th }}$ ed. Philadelphia: Elsevier; 2015. p. 1258-80.

7. Jones AS. Malignant tumours of the Salivary Glands. In: Gleeson M, Clarke RC, editors. Scott-Brown's Otorhinolaryngology, Head and Neck Surgery. $7^{\text {th }}$ ed. London: CRC Press; 2008. p. 2493-2521. 